\title{
Optimization of the Natural-Technical System "Iron Ore Quarry" Management Based on the Algorithm of the Rock Mass Stability Ensuring
}

\author{
L. Yarg ${ }^{(凶)}$, I. Fomenko, and D. Gorobtsov \\ Department of Engineering Geology, \\ Russian State Geological Prospecting University (MGRI), Moscow, Russia \\ ifolga@gmail.com
}

\begin{abstract}
The method of natural-technical system (NTS) "Iron ore deposits" optimal control in terms of the pit walls stability is based on two-level systems with cross-links. The algorithm for optimizing the pit walls angles designed values includes the following steps: separation of rock massif into engineeringgeological complexes (EGC), typing of the pit walls within the EGC, substantiation of the calculation geomechanical models and stability analysis of the pit walls based on mathematical modeling. Based on the results of the calculations the maximum angle of the pit wall is determined at which it remains stable. As minimized performance criteria the deviations of the stability factors current state from the maximum allowable values are considered. The proposed approach is one of the ways to ensure the stability of the deep-pit quarries walls during their long-term development.
\end{abstract}

Keywords: Natural-technical system (NTS) - Open pit • Stability assessment • Optimization of pit walls angles $\cdot$ Control of NTS

\section{Introduction}

The development of iron ore deposits and permanent deepening of the open pit leads to changes in the stress state, decompaction of rocks, an increase in massif fracture, weathering rates and a decrease in the strength properties of rocks that form the open pit, activation of geological processes: debris, rock falls, landslips and landslides, suffusion, surface erosion.

The considered natural-technical system "Ore deposits of KMA" is a complex system of the local level. The functioning of the local NTS "Iron Ore Quarry" is characterized by: a certain set of processes developing permanently without the stabilization stage under the influence of long-term man-made interactions which form the basis of the NTS operation. Reduction of negative consequences is possible only with a clear understanding of the processes developing in the field of interaction of naturaltechnical systems (NTS) "mining and processing plant (GOK") (Yarg et al. 2018).

Research objective: optimization of the NTS "iron ore quarry" management based on the algorithm of the rock mass stability ensuring. 


\section{Methods and Approaches}

The processes development initiated by technological work is progressive in space and time. Long-term exploration of deposits leads to the changes of boundaries, mode and set of processes (Bondarik and Yarg 2015).

The system of engineering geological support in the quarry areas includes a range of work and research aimed to obtain the information about engineering geological conditions during the entire life of the quarry, assessment and forecast of the slope stability at various stages of their construction to achieve the technical, economic and environmental safety of mining work.

Effective management of the natural-technical system "Iron Ore Deposit KMA" should be carried out taking into account both local and global stability factors of the pit walls.

Separation of the Rock Massif to EGC. Features of engineering-geological conditions including lithologic-petrographic composition, physical and mechanical properties, structural disturbance, parameters of the natural stress field require an individual approach to the process of predicting the behavior of an array of rocks. This becomes possible only on the basis of correct engineering and geological research data.

Elementary NTS "Stoilensky Quarry" is divided into two engineering-geological complexes (Yarg et al. 2018):

- The upper one is composed of loose and semi-rock soils with a thickness up to $90 \mathrm{~m}$. The sedimentary cover is typified taking into account the geological structure, hydrogeological conditions (the water inflow along the open-pit contour water permeability) and the physical and mechanical properties of the soils.

- The lower EGC is represented by rocks with a thickness of up to $600 \mathrm{~m}$. The main stability determining factors are: anisotropy of the massif properties due to its fracturing and spatial orientation of the cracks.

Engineering geological processes developing during the operation of the elementary NTS "Open pit" of the iron ore deposits of Stoilensky and Lebedinsky GOK are: scree formation; collapse; landslides; surface erosion; suffusion: mechanical, chemical; filtration deformations.

Tiping of the Pit Walls Within the EGC. A "bowl” of a quarry with a simple structural plan of the rock mass (Fomenko et al. 2016, Hoek and Bray 1981, Wyllie and Mah 2010) (i.e. assuming that the direction of weak zones and fracturing within the pit remains constant) can be divided into zones of conditional stability and potential instability of the walls (Fomenko et al. 2016).

In accordance with these factors, three types of pit walls quarrying were identified: relatively difficult, difficult and very difficult.

\section{Results and Discussion}

Optimization of the NTS "Mineral Deposit" functioning is based on a modern methodology for stability calculation (Pendin and Fomenko 2015, Bar et al. 2018). 
For potentially unstable pit wall the probable collapse can occur according to the following schemes:

1. The azimuth of crack systems fall coincides with the azimuth of the pit wall fall. In this case a flat problem can be solved.

2. The azimuth of crack systems fall does not coincide with the azimuth of the pit wall fall, but at the same time according to the kinematic analysis results the formation of wedge-type collapses is likely. In this case the pit wall stability problem is solved in a three-dimensional formulation, for example using the method of volume blocks.

Based on the results of the calculations the maximum pit wall angle is determined at which it remains stable.

In accordance with the "large-scale interconnected" theory (Tsurkov and Litvinchev 1994), the management of local NTS "Iron Ore Quarry" in terms of the pit walls stability can be based on two-level systems with cross-links. As minimized performance criteria the deviations of the stability factors current state from the maximum allowable values are considered. As optimized parameters the following were taken: the level of the upper Jurassic aquifer, the strength properties of AlbCenomanian sands and Devonian clays, fracturing and blockiness of the Precambrian massif.

The graphs (Figs. 1, 2 and 3) of the relation between safety factor and the dynamics of aquifer, blockiness and strength properties of rocks allow setting the limit values of the system coordinates at which the system does not leave the zone of admissible states.

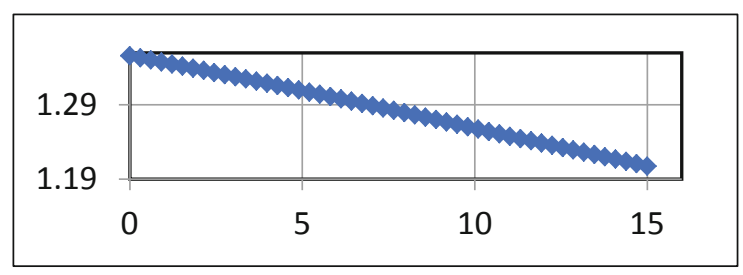

Fig. 1. The effect of groundwater level rise (horizontal axis) on the global safety factor of the pit walls (vertical axis).

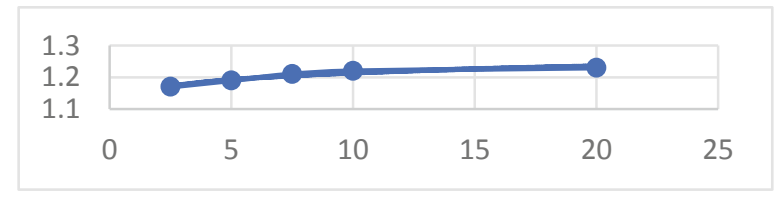

Fig. 2. The relation between $\mathrm{Ku}$ (vertical axis) and the blockiness of the rock massif (distance between cracks), (horizontal axis) 


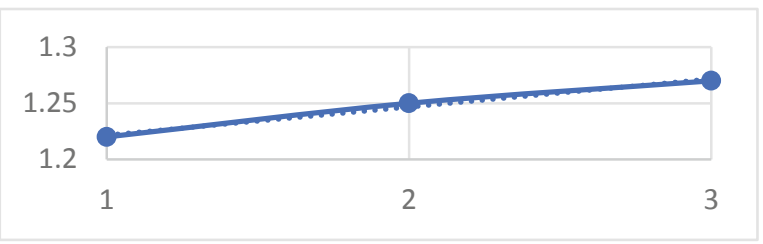

Fig. 3. The effect of the ore-crystalline rocks strength (horizontal axis) in the massif on the safety factor (vertical axis): 1 - densely fractured rocks; adhesion $\mathrm{C}=690 \mathrm{kPa}$, angle of internal friction $\varphi=32^{\circ} ; 2-$ moderately fractured, adhesion $\mathrm{C}=1130 \mathrm{kPa}$, angle of internal friction $\varphi=36^{\circ} ; 3-$ weakly fractured, adhesion $\mathrm{C}=3140 \mathrm{kPa}$, angle of internal friction $\varphi=39^{\circ}$

\section{Conclusions}

The obtained results are in good agreement with the generally accepted ideas about the causes of stability infraction in the massif zones near the pit walls. At the same time the obtained data advantage is the possibility of establishing the limiting values of changes in the safety factors on graphs. These safety factors determine both local and global stability of the pit walls at which the system will not leave the zone of admissible states.

Control solutions that ensure the safe work performance should include: adjustment of the drainage system and water supply process, taking into account the position of the GWL; interception and organized disposal of surface and seepage water into the circulating system; maintaining the water level in the settling ponds, excluding flooding of the territory; adjustment of the blasting operations technology during the quarrying of deep horizons taking into account the stress state of the massif and the occurrence of the rock technogenic fracturing during drilling and blasting operations.

The obtained predictive estimates of the pit walls stability can be used in the design and development of fields with similar engineering geological conditions.

\section{References}

Bar N, Weekes G, Welideniya S (2018). Benefits and limitations of applying directional shear strengths in $2 \mathrm{D}$ and $3 \mathrm{D}$ limit equilibrium models to predict slope stability in highly anisotropic rock masses. https://www.researchgate.net/profile/Neil_Bar/research

Bondarik GK, Yarg LA (2015) Engineering geology. Questions of theory and practice. Philosophical and methodological foundations of geology. KDU (in Russian)

Fomenko IK, Pendin VV, Gorobtsov DN (2016) Estimation of the stability of quarries of quarries in rocky soils. Min Sci Technol (3), 10-21 (in Russian)

Hoek E, Bray JW (1981) Rock slope engineering, 3rd edn. Institution of Mining and Metallurgy, London

Pendin VV, Fomenko IK (2015) Methodology of landslide hazard assessment and forecast. Publishing House of the Russian Federation Lenand, Moscow (in Russian) 
Tsurkov VI, Litvinchev IS (1994) Decomposition in dynamic problems with cross-links. Science: Physics and Mathematics, Moscow (in Russian)

Wyllie DC, Mah CW (2010) Rock slope engineering: civil and mining, 4rd edn. Spon Press/Taylor\&Francis Group, London

Yarg LA, Fomenko IK, Zhitinskaya OM (2018) Evaluation of slope optimization factors for long-term operating open pit mines (in terms of the Stoilensky iron ore deposit of the Kursk Magnetic Anomaly). Gornyi Zhurnal (11), 76-81

Open Access This chapter is licensed under the terms of the Creative Commons Attribution 4.0 International License (http://creativecommons.org/licenses/by/4.0/), which permits use, sharing, adaptation, distribution and reproduction in any medium or format, as long as you give appropriate credit to the original author(s) and the source, provide a link to the Creative Commons license and indicate if changes were made.

The images or other third party material in this chapter are included in the chapter's Creative Commons license, unless indicated otherwise in a credit line to the material. If material is not included in the chapter's Creative Commons license and your intended use is not permitted by statutory regulation or exceeds the permitted use, you will need to obtain permission directly from the copyright holder.

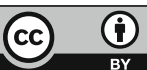

